\title{
Unusually strong nitric oxide descent in the Arctic middle atmosphere in early 2013 as observed by Odin/SMR
}

\author{
K. Pérot, J. Urban, and D. P. Murtagh \\ Chalmers University of Technology, Department of Earth and Space Sciences, Gothenburg, Sweden \\ Correspondence to: K. Pérot (kristell.perot@chalmers.se)
}

Received: 20 December 2013 - Published in Atmos. Chem. Phys. Discuss.: 10 February 2014

Revised: 28 May 2014 - Accepted: 23 June 2014 - Published: 12 August 2014

\begin{abstract}
The middle atmosphere was affected by an exceptionally strong midwinter stratospheric sudden warming (SSW) during the Arctic winter 2012/2013. These unusual meteorological conditions led to a breakdown of the polar vortex, followed by the reformation of a strong upper stratospheric vortex associated with particularly efficient descent of air. Measurements by the submillimetre radiometer (SMR), on board the Odin satellite, show that very large amounts of nitric oxide (NO), produced by energetic particle precipitation (EPP) in the mesosphere/lower thermosphere (MLT), could thus enter the polar stratosphere in early 2013. The mechanism referring to the downward transport of EPP-generated $\mathrm{NO}_{\mathrm{x}}$ during winter is generally called the EPP indirect effect. SMR observed up to 20 times more $\mathrm{NO}$ in the upper stratosphere than the average NO measured at the same latitude, pressure and time during three previous winters where no mixing between mesospheric and stratospheric air was noticeable. This event turned out to be the strongest in the aeronomy-only period of SMR (2007present). Our study is based on a comparison with the Arctic winter 2008/2009, when a similar situation was observed. This outstanding situation is the result of the combination of a relatively high geomagnetic activity and an unusually high dynamical activity, which makes this case a prime example to study the EPP impacts on the atmospheric composition.
\end{abstract}

\section{Introduction}

Energetic particle precipitation (EPP) refers to the process by which energetic protons and electrons affect the Earth's middle atmosphere. It leads, amongst other things, to the production of nitric oxide (NO) in the high-latitude meso- sphere and lower thermosphere (MLT) via a cascade of dissociation, ionization and recombination processes (e.g. Rusch et al., 1981). In the polar lower thermosphere and uppermost mesosphere, NO is mainly produced by precipitation of lowenergy (auroral) electrons (energy $<30 \mathrm{keV}$ ) and protons (energy $<1 \mathrm{MeV}$ ) (Thorne, 1980). Regular precipitation of medium energy electrons (30-300 keV) results in nitric oxide production at mesospheric altitudes (Codrescu et al., 1997), but the interaction between these particles and the Earth's atmosphere is not yet well understood. NO generated by EPP is referred to as EPP-NO. Its photochemical lifetime is only a few days in the sunlit mesosphere. However, in winter polar night conditions, NO has a lifetime long enough to be transported down to the stratosphere by the meridional circulation without being photochemically destroyed. As it descends in the polar region, $\mathrm{NO}$ is partly converted to nitrogen dioxide $\left(\mathrm{NO}_{2}\right)$. They form together the $\mathrm{NO}_{\mathrm{x}}$ chemical family which is involved in catalytic ozone $\left(\mathrm{O}_{3}\right)$ destruction and plays an important role in atmospheric chemistry (Solomon et al., 1982). The descent of $\mathrm{NO}_{\mathrm{x}}$ from the MLT to the stratosphere is generally called the EPP indirect effect (EPP IE). It has already been described by a number of authors (e.g. Siskind et al., 2000; Funke et al., 2005; Randall et al., 1998, 2009).

This mechanism is controlled both by space weather and middle atmosphere dynamics. It depends on the EPP-NO $\mathrm{N}_{\mathrm{x}}$ production level, itself linked to solar activity. Auroral particles, which represent one of the main sources of NO in the MLT, are trapped into the magnetospheric field lines. When the geomagnetic field is disturbed by high-speed solar wind or solar coronal mass ejections, these energetic particles can reach the atmosphere and generate large amounts of NO in the polar regions. It has been shown that the Ap index, which is a proxy for geomagnetic activity over the globe, is 
correlated with the auroral NO production in the absence of unusual dynamics (e.g. Randall et al., 2007; Sheese et al., 2011). Energetic particle precipitation represents therefore an important solar-terrestrial coupling mechanism. The EPP indirect effect is also strongly linked to transport. This second factor plays an important role, especially in the Northern Hemisphere $(\mathrm{NH})$ where dynamical variability is higher than in the south (Randall et al., 2007). Exceptional dynamical conditions can lead to surprisingly strong EPP IE. Such a situation has been observed several times during the last decade. Using Odin/submillimetre radiometer (SMR) data over the period 2001-2009, Orsolini et al. (2010) presented evidence for an anomalously strong descent of mesospheric air into the upper stratosphere in the Arctic region in three winters over the 8 analysed years. The 2008/2009 NH polar winter in particular was characterized by an unusually strong and persistent midwinter stratospheric sudden warming (SSW) (Labitzke et al., 2009; Manney et al., 2009). SSW is a phenomenon that takes its name from a rapid temperature increase of several tens of kelvin over a few days at high latitude. It is triggered by planetary-scale wave motions propagating upward from the troposphere. They break when reaching the stratosphere, releasing their energy and disturbing the polar vortex. It is important to highlight that only midwinter warmings are considered in this study. For that kind of events, a coherent stratospheric polar vortex is reestablished, contrary to final warmings that cause the definitive breakdown of the vortex at the end of the winter. The 2009 SSW event was characterized by a full breakdown of the vortex, followed by the reformation of a strong upper stratospheric vortex associated with very efficient descent of air. Randall et al. (2009) showed that very large amounts of $\mathrm{NO}_{\mathrm{x}}$ could thus enter the stratosphere despite a level of geomagnetic activity well below average, which clearly demonstrates the importance of dynamical modulations of EPP IE.

It will be shown in this paper that the 2012/2013 polar winter was also affected by an exceptionally strong midwinter SSW followed by an elevated stratopause (ES) event. Unusually large amounts of EPP-generated NO were transported downward into the Arctic stratosphere and lower mesosphere in early 2013. The purpose of this work is to describe this event, based on the analysis of Odin/SMR observations, and to present a basic comparison with the case of 2009, which has been so far considered as a record-breaking winter in terms of stratospheric warming (Labitzke et al., 2009; Manney et al., 2009; Randall et al., 2009). The concentration of nitric oxide is an important quantity to monitor since this species is involved in $\mathrm{O}_{3}$ depletion, which plays a crucial role in atmospheric chemistry. The results presented here can contribute to a better understanding of its variability. They will be described in Sect. 2 and discussed in Sect. 3.

\section{Results}

\subsection{The submillimetre radiometer}

Odin is a small Swedish-led research satellite, in cooperation with the Canadian, French and Finnish space agencies, launched in 2001 (Murtagh et al., 2002). It was initially dedicated to aeronomy and astronomy, but has only been used for aeronomy observations since April 2007. It has also been a European Space Agency (ESA) third party mission since the same year.

The submillimetre radiometer is one of the instruments aboard Odin. It is a limb emission sounder measuring globally a variety of trace gases as well as temperature in the whole middle atmosphere. The work presented in this paper is based on the measurements performed by this instrument. Water vapour $\left(\mathrm{H}_{2} \mathrm{O}\right)$ is retrieved from a strong thermal emission line at $557 \mathrm{GHz}$, providing information from $\sim 40$ to $100 \mathrm{~km}$ with an altitude resolution of about $3 \mathrm{~km}$. Temperature data are derived simultaneously from the same band in the $\sim 40-90 \mathrm{~km}$ altitude range. Retrieval and error analyses for these measurements, as well as a comparison study with measurements from ACE-FTS, are described in detail by Lossow et al. (2007). SMR temperature and water vapour derived from this channel were used, for example, by Orsolini et al. (2010) to study the dynamics of the polar middle atmosphere. SMR also observes NO thermal emission lines in a band centred near $551.7 \mathrm{GHz}$. The vertical resolution for this species is $\sim 7 \mathrm{~km}$ in the upper stratosphere and in the mesosphere. NO data are available from 2003 on the basis of 1 measurement day per month. As noted above, the instrument has been entirely dedicated to the Earth observation since 2007. NO measurements could therefore be performed much more frequently after this date, on an irregular basis of 2 observation days in a 14-day cycle (approximately 4 days month $^{-1}$ ). More details about these measurements are given by Sheese et al. (2013). For our study, only the observations made after 2007, with a good temporal sampling, have been used. After communication with the Envisat satellite was lost in April 2012, SMR is at present the only instrument providing NO measurements with full global coverage (including the polar winter regions).

\subsection{Middle atmospheric dynamical activity}

Figure 1 represents the state of the middle atmosphere during the Arctic winter 2012/2013, from November to May, in the vertical range $2-0.003 \mathrm{hPa}$ (approximately $40-90 \mathrm{~km}$, which is the altitude range in which Odin/SMR temperature data are available). SMR measurements are plotted in the two first panels. Figure 1a shows the evolution of zonal mean temperatures poleward of $70^{\circ}$. A clear increase of the temperature appears in the upper stratosphere, around $1 \mathrm{hPa}$, in early January. This stratospheric warming is associated with a mesospheric cooling, clearly visible around $0.03 \mathrm{hPa}$. The black 


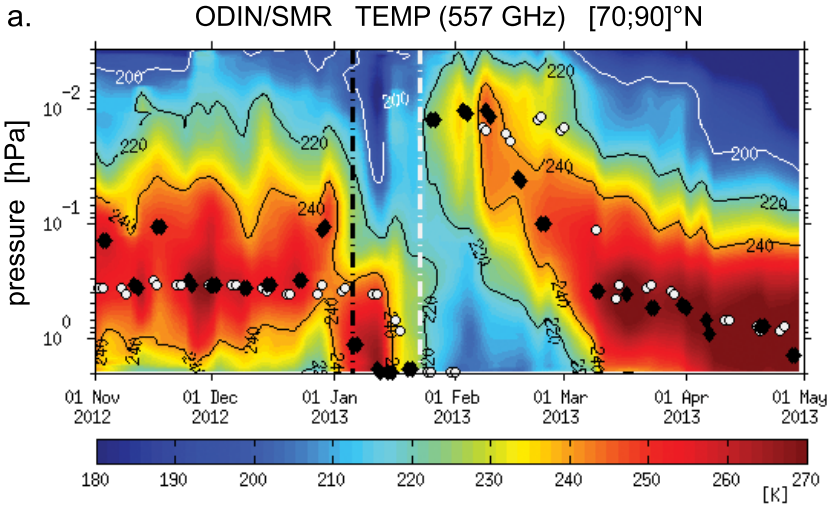

b. ODIN/SMR H2O $(557 \mathrm{GHz}) \quad[70 ; 90]^{\circ} \mathrm{N}$

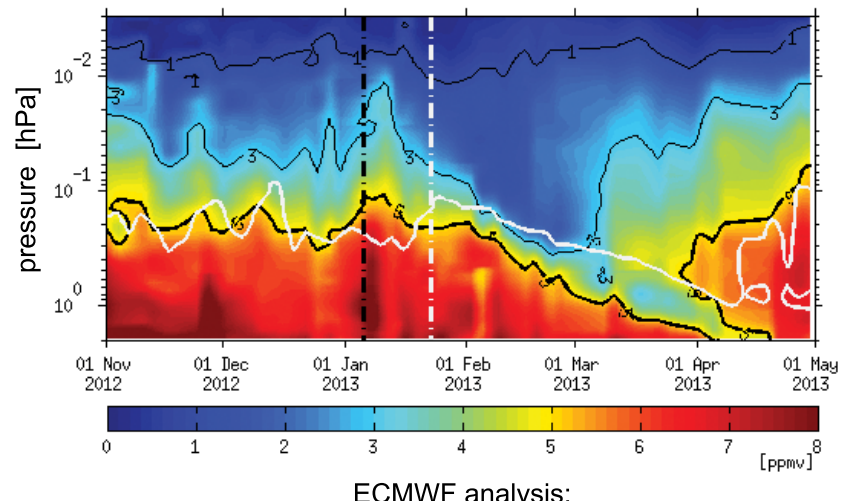

C. Daily mean zonal mean zonal wind at $60^{\circ} \mathrm{N}$ and $10 \mathrm{hPa}$

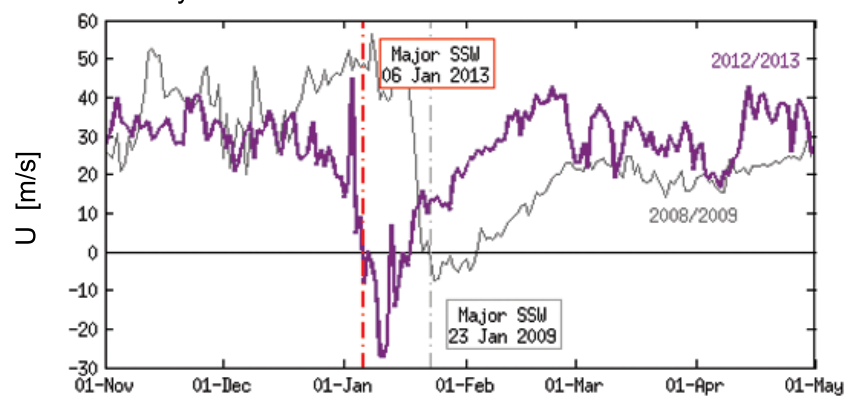

Figure 1. (a) Upper stratosphere/mesosphere pressure-time section of SMR zonal mean temperature in the $70-90^{\circ}$ latitude band during the Arctic winter 2012/2013. Black diamonds indicate the zonal average stratopause height, and the black dash-dotted line indicates the central date of the warming. For comparison, overlaid white dots and white dash-dotted line correspond to the same parameters for the 2009 event. (b) Same as (a) but for SMR zonal mean $\mathrm{H}_{2} \mathrm{O}$ volume mixing ratio. The thick black contour is associated with volume mixing ratio values of $5 \mathrm{ppmv}$. The same contour measured in 2008/2009 (solid white line) is overlaid for comparison. (c) Daily mean zonal mean zonal wind at $60^{\circ} \mathrm{N}$ and $10 \mathrm{hPa}$ from ECMWF analyses during the Arctic winters 2008/2009 (thin grey line) and 2012/2013 (thick purple line). The dash-dotted lines indicate the central dates of these warmings.

diamonds indicate the maximum of the temperature profile in the vertical range considered. They represent the stratopause, which clearly descends immediately after the warming event, but reforms at a particularly high altitude (around $80 \mathrm{~km}$ ) in the following weeks. The white dots, overlaid for comparison, show the evolution of the stratopause height during the winter 2008/2009, as inferred from temperature measurements from SMR. As explained in Sect. 1, both winters were characterized by a particularly strong SSW event. This plot shows that the behaviour of the temperature structure was very similar in both cases. Such elevated stratopause events are most of the time observed during winter when the middle atmospheric zonal wind structure is disturbed by a SSW (Chandran et al., 2013).

The bottom panel of Fig. 1 shows how the typical wintertime circulation was disrupted in early 2009 (thin grey line) and in early 2013 (thick purple line). For this plot, wind fields from the European Centre for Medium-range Weather Forecast (ECMWF) operational analyses have been used as ancillary meteorological data. According to the World Meteorological Organization (WMO), a major midwinter warming occurs when the zonal mean zonal winds at $60^{\circ} \mathrm{N}$ and $10 \mathrm{hPa}$ become easterly during winter (between November and March) (Andrews et al., 1985). In addition to the reversal of the winds, the WMO definition requires that the $10 \mathrm{hPa}$ zonal mean temperature gradient between $60^{\circ}$ and $90^{\circ} \mathrm{N}$ is positive. The first day on which the zonal wind reverses is defined as the central date of the SSW event. As shown in Fig. 1c, this occurred on 23 January 2009 and on 6 January 2013. The temperature gradients also reversed poleward of $60^{\circ}$ (not shown here). The criteria for a major midwinter warming have therefore been fulfilled for these two winters. Like in 2009 (Manney et al., 2009), the shift in wind direction that occurred in early 2013 was associated with the splitting of the polar vortex into two smaller vortices. This phenomenon is clearly visible in $\mathrm{N}_{2} \mathrm{O}$ fields from SMR (not shown here. A more detailed dynamical analysis of this latest SSW event is presented by Goncharenko et al. (2013)). We can see in Fig. 1c that the zonal wind stayed easterly for about 10 days and then reversed again, both in 2009 and in 2013. The easterlies were clearly stronger in 2013 than in 2009. In both cases, the vortex fully recovered in late February, but, in 2009, contrary to what happened in 2013, the wind speed did not reach values comparably high as before the warming.

Figure $1 \mathrm{~b}$ represents the vertical-time section of zonal mean $\mathrm{H}_{2} \mathrm{O}$ volume mixing ratios (VMRs) measured by SMR between November 2012 and May 2013. Water vapour is a very good tracer for the dynamical processes in the middle atmosphere (e.g. Orsolini et al., 2010). Here, for example, looking at the 3 and 5 ppmv contours allows a good visualization of the evolution of air masses throughout the winter. In November and December, at a given pressure level, mixing ratios slightly drop in time as a result of early winter descent of air due to the meridional mesospheric circulation (more pronounced on the 3 ppmv contour). This evolution is interrupted by a brief increase of VMR values in early January, explained by an upward motion of $\mathrm{H}_{2} \mathrm{O}$-rich air, associated 
with the disruption of the polar vortex during the warming event. This also might be due to mixing of midlatitude air into the polar regions. This observation is consistent with the results of Tweedy et al. (2013). An anomalous descent of dry air from the mesosphere is clearly observed thereafter. The 5 ppmv contour (thick black line) highlights this strong downward motion, which is associated with the recovery of the vortex. It descends from about $0.1 \mathrm{hPa}(\sim 63 \mathrm{~km})$ in mid-January to below $2 \mathrm{hPa}(\sim 41 \mathrm{~km})$ in the second week of April, which corresponds to a nearly linear descent rate of approximately $-270 \mathrm{mday}^{-1}$. This phenomenon is an important coupling mechanism between the MLT and the stratosphere. The thick white line, overlaid for comparison, corresponds to the evolution of the 5 ppmv $\mathrm{H}_{2} \mathrm{O}$ VMR contour measured by SMR throughout the winter 2008/2009. With a subsidence rate of approximately $-225 \mathrm{~m} \mathrm{day}^{-1}$, the vortex seems to be significantly weaker in 2009 than in 2013. Moreover, this figure shows that the tongue of dry air observed by SMR extended at least $5 \mathrm{~km}$ lower in the stratosphere in 2013 than in 2009. These results are perfectly consistent with the study carried out by Holt et al. (2013), which showed that the earlier a SSW event occurs in the winter season, and the stronger is the descent following the event.

\subsection{Energetic particle precipitation indirect effect}

Figures $2 \mathrm{a}$ and $\mathrm{b}$ show the evolution of zonally averaged NO mixing ratio in the Arctic region during the 2008/2009 and 2012/2013 winters. As previously explained, both of these winters were characterized by a particularly efficient descent of air due to the reformation of the polar vortex after a major midwinter warming event. SMR observations of NO illustrate the dynamical modulations of the EPP indirect effect during these two particular winters. The white dash-dotted lines indicate the central date of the warming events. A slight depletion of NO in the upper stratosphere and mesosphere is visible in January, immediately after this date. This is due to the upward transport of $\mathrm{H}_{2} \mathrm{O}$-rich, NO-poor air, as seen in Fig. 1, and it also might be a signature of poleward mixing. This observation fits with the modelling study by Tweedy et al. (2013), which shows a hint of such a decrease. In both 2009 and 2013, very large amounts of NO descended quickly into the upper stratosphere. SMR measured at least $40 \mathrm{ppbv}$, around $0.4 \mathrm{hPa}(\sim 55 \mathrm{~km}), 2$ months after the central date of the SSW event, in both years. When looking at this figure, it is important to keep in mind that not only the transport can have an impact on NO mixing ratios but photochemistry as well. Under sunlit conditions, stratospheric $\mathrm{NO}_{2}$ is converted into NO, as explained by Funke et al. (2011). This reaction can therefore lead to a slight increase in NO abundances after the end of the polar night (from March), when SMR measurements are performed both during daytime and nighttime. Moreover, the vortex is not always located above the pole. It can be shifted away, especially when the middle atmospheric wind structure is disturbed by a SSW event.

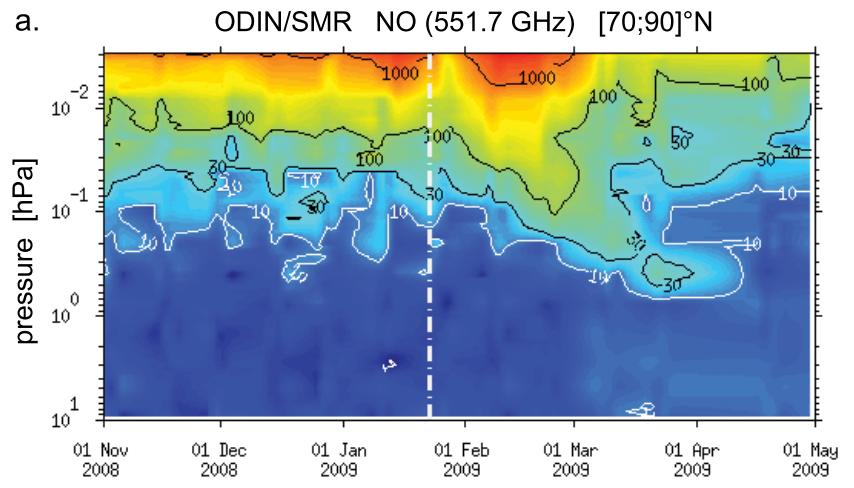

b.

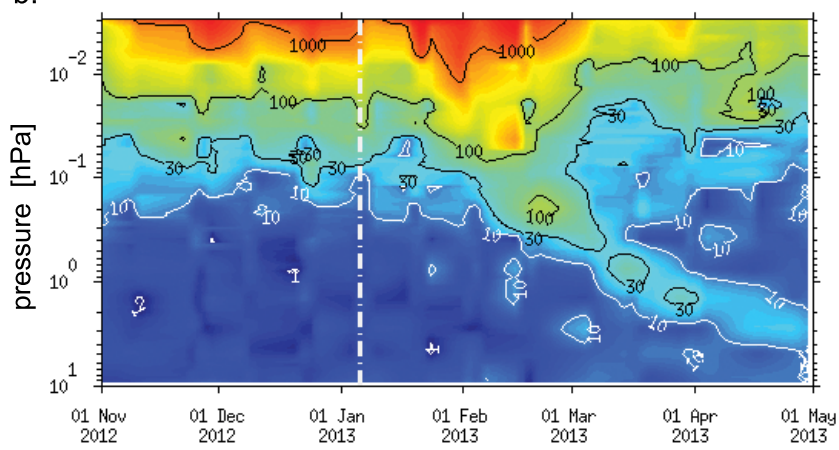

c. ODIN/SMR average NO observed in $2008,2010 \& 2011[70 ; 90]^{\circ} \mathrm{N}$

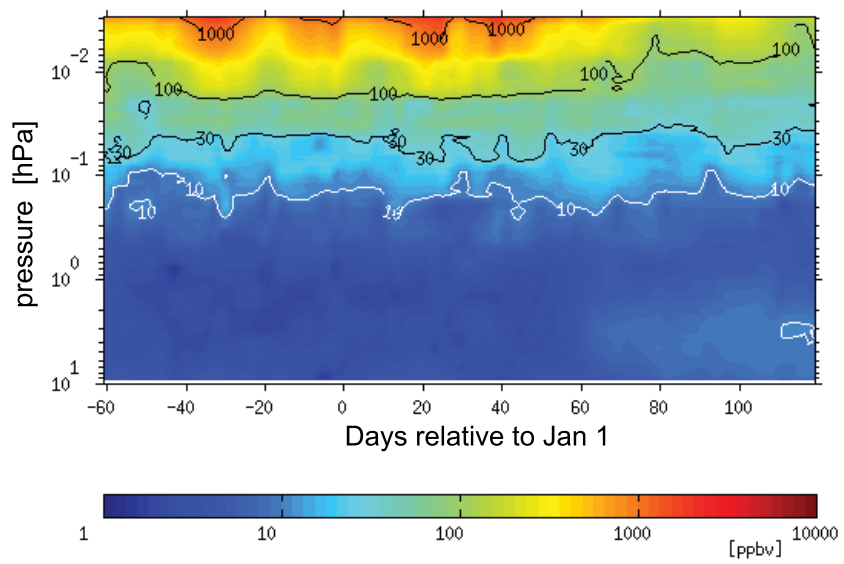

Figure 2. Upper stratosphere/mesosphere pressure-time sections of SMR zonal mean NO mixing ratio in the NH high latitudes (poleward of $70^{\circ} \mathrm{N}$ ), from 1 November to 1 May, for the Arctic winter seasons 2008/2009 (a) and 2012/2013 (b). The white dash-dotted lines indicate the central date of the warmings. Panel (c) represents the average NO measured during winters 2007/2008, 2009/2010 and 2010/2011, when no downward transport of NO was noticeable in the SMR data set.

Consequently, even if the measurements represented in Fig. 2 have mainly been done inside the vortex, there can also be a slight influence of some mixing with the air from outside the vortex. Using equivalent latitude as a coordinate can decrease the effect of this mixing. In this case, the air masses we are looking at would be more likely located inside the 


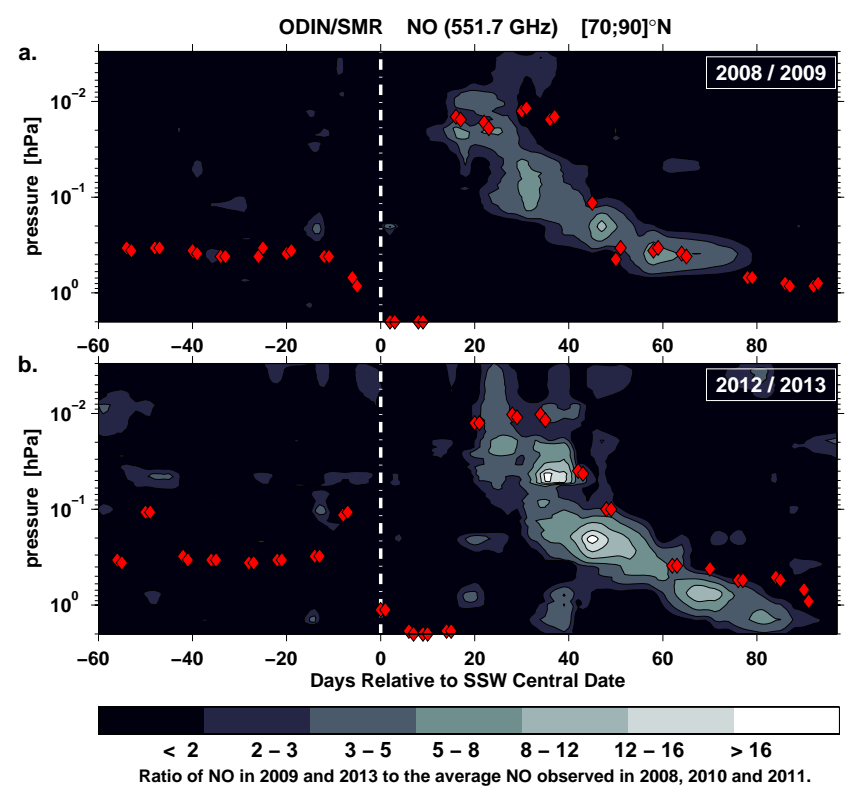

Figure 3. Relative NO enhancements: ratio of nitric oxide in $2008 / 2009$ and 2012/2013 to the average NO measured at the corresponding latitude, pressure and time in 2007/2008, 2009/2010 and 2010/2011. Time is expressed in days relative to the central date of each SSW event (white dash-dotted lines) to make the comparison easier. Red diamonds indicate the height of the stratopause as inferred from SMR temperature measurements.

vortex, at least below $3000 \mathrm{~K}(\sim 0.1 \mathrm{hPa}, \sim 60 \mathrm{~km})$ (Harvey et al., 2009). The same plots have therefore been made with NO measurements performed in the $[70-90]^{\circ} \mathrm{N}$ equivalent latitude range (not shown). Equivalent latitude is calculated from ECMWF PV fields, which are unfortunately available only up to the lower mesosphere. As a result, only the bottom part of the descent event can be observed. As expected, the descent pattern was slightly more pronounced and more continuous. But, in the limited altitude range available, we found that the overall pattern was very similar. That is a confirmation that Fig. 2 gives a good representation of the phenomenon.

Figure 3 represents the relative NO enhancements for the Arctic winters 2008/2009 and 2012/2013. The goal is to compare the EPP indirect effect for these 2 years. All measurements done after 2007, when the temporal sampling of the instrument was much better than during 2003-2007, have been considered in this study. Nitric oxide measurements from Odin/SMR have been analysed for each of these six winter seasons. In 2007/2008 and 2010/2011, no significant dynamical event disturbed the middle atmosphere in the middle of the winter. The EPP-induced NO stayed in the MLT, and EPP IE was therefore very low. Nitric oxide measurements performed by SMR before 2010 are consistent with $\mathrm{NO}_{\mathrm{x}}$ observations by ACE-FTS described by Randall et al. (2009). A SSW event occurred in late January 2010. However no particular NO downward transport has been observed, and the
EPP IE was very low that year as well. This can be explained by the fact that this warming event was dynamically very weak. No mixing between mesospheric and stratospheric air masses was noticeable in the SMR data set. In addition, the geomagnetic activity was particularly low. The average Ap index from 1 October 2009 to 1 March 2010 was 3.1 only, and never exceeded 14 (data from ftp://ftp.ngdc.noaa.gov/ STP/GEOMAGNETIC_DATA/INDICES/KP_AP/). As previously explained, fewer auroral particles are likely to precipitate in the atmosphere in such a situation, so little NO was probably produced in the MLT. The winter 2009/2010 can therefore be considered as dynamically quiet with respect to NO. As for the winter 2011/2012, a quite uncommon situation was observed. This winter was affected by a minor stratospheric warming in January (followed by the formation of an elevated stratopause) and by a solar proton event (SPE) approximately at the same time. A series of coronal mass ejections generated intense particle fluxes of high energy, which could penetrate deep into the Earth's atmosphere in the polar regions and dramatically alter the middle atmospheric composition (von Clarmann et al., 2013). This mechanism is generally called the EPP direct effect. In January 2012, this effect was superimposed on the subsidence of mesospheric NO-rich air associated with the SSW-ES event, making the EPP IE more challenging to observe. That is the reason why we decided not to include this winter in our study.

The NO mixing ratios measured during the three winters 2007/2008, 2009/2010 and 2010/2011 have been averaged in order to get an estimate of the background levels during quiet conditions. This 3-year mean is represented in Fig. 2c. Because of the lack of a more valid climatological reference, it will be considered as a reference for the standard NO winter distribution in the Arctic region. A slight increase in NO mixing ratios is noticeable in this figure in the stratosphere from March to May. This seasonal variation is due to the sampling pattern of the observations which covers different photochemical conditions for different times, as previously explained.

The ratio of nitric oxide measured by SMR in 2008/2009 and 2012/2013 to this reference background has been calculated and plotted in Fig. 3. A tongue of increased NO VMR for both winters is clearly visible. There could possibly be an influence of the seasonal variation, but this one would be very small, as the seasonal signal is negligible compared to the EPP IE (as seen in Fig. 2). The red diamonds represent the height of the stratopause as observed by Odin/SMR. It appears that the onset of the enhancements coincides exactly with the formation of the elevated stratopause, which is due to an interplay between gravity wave and planetary wave forcing, as explained by Limpasuvan et al. (2012). In both years, at least 3 times more NO than average is observed between $\sim 70$ and $85 \mathrm{~km}$ immediately after the ES event. The high NO tongue stays just below the stratopause, following its evolution in altitude and time for at least 2 months. 


\section{Summary and discussion}

The major stratospheric warming and the following elevated stratopause event that occurred in January 2009 were unusually strong and persistent in time, as shown by Manney et al. (2009). We have seen in the previous section that the 2013 SSW-ES event was characterized by a very efficient downward motion, associated with an even higher subsidence rate than in 2009. As it appears in SMR measurements (Fig. 2), the downward transport of NO can be strongly amplified during the Arctic winters affected by such events. NO formed in the MLT by the impact of energetic particles was indeed transported down to the mesosphere and upper stratosphere in very large amounts during the months following these two stratospheric warmings. Figure 3 shows that the 2013 SSWES event led to significantly larger NO mixing ratio enhancements than the equivalent event that occurred in 2009. Up to 20 times more NO than average was observed in the upper stratosphere, whereas this ratio did not exceed a value of $\sim 9$ in 2009. If we consider all of the points associated with a value greater than 3 (Fig. 3), the mean excess NO is 4.9 in 2013, while it is only 4.0 in 2009 . Moreover, the tongue of EPP-NO extends much lower in altitude (below $\sim 40 \mathrm{~km}$ vs. $\sim 50 \mathrm{~km}$ in 2009). It is also significantly more extended in time (93 days after the SSW central date vs. 79 days in 2009). The 2013 SSW-ES event has therefore a higher potential to affect the stratospheric composition. However, we can notice that both NO tongues do not reach the maximum of the primary ozone layer. The differences between these two winters can be explained by the earlier onset of the dynamical event in 2013 compared to 2009. Holt et al. (2013) indeed showed that the EPP indirect effect is larger for earlier central warming dates for two main reasons: the earlier an event occurs in the winter season, the stronger is the following descent, and the longer the EPP-NO $\mathrm{N}_{\mathrm{x}}$ can be transported down before the final warming occurs. This highlights the importance of the dynamics for the EPP IE.

The effects of energetic particle precipitation on the atmosphere are governed not only by dynamics but also by solar activity. The winter 2012/2013 was close to the solar maximum of the solar cycle 24 , whereas the winter 2008/2009 corresponded to the solar minimum. The average Ap index from 1 October 2012 to 1 March 2013 was quite high: 6.6 with a maximum of 47 , while it was just 4.8 and never exceeded 34 for the same period 4 years earlier (data from ftp://ftp.ngdc.noaa.gov/STP/GEOMAGNETIC_DATA/ INDICES/KP_AP/). The geomagnetic activity was therefore relatively high during the 2012/2013 winter. As explained in Sect. 1, such a situation is favourable to a higher NO production level in the upper mesosphere and lower thermosphere. This is consistent with the observations by SMR, which measured higher nitric oxide mixing ratios. The averaged VMR around an altitude of $90 \mathrm{~km}$ between November and March was approximately 1800 ppbv in 2012/2013, versus $1240 \mathrm{ppbv}$ in $2008 / 2009$. Consequently, more NO was available to be transported down to lower altitudes in early 2013. This outstanding EPP IE was therefore the result of the combination of a high geomagnetic activity and an exceptionally high dynamical activity. All the elements were gathered for a particularly strong EPP indirect effect, which makes the 2013 event a very good example of how the solar activity can influence the Earth's atmosphere.

The results presented in our paper show that the NO descent observed during the Arctic winter 2012/2013 corresponds to the strongest EPP indirect effect during the period when Odin/SMR performed regular measurements of NO (2007 to present). However, some other examples of EPP IE have been previously observed by other instruments, in particular in early 2004, which is so far considered as the largest case on record (Holt et al., 2012; Funke et al., 2014). Holt et al. (2012) showed that energetic particle precipitation contributed to the deposition of $2.7 \mathrm{Gmol}$ of $\mathrm{NO}_{\mathrm{x}}$ into the stratosphere during this winter. It would be interesting to quantify the total amount of EPP-NO deposited into the stratosphere in early 2013 and to compare this result to the other events on record.

The indirect effect of energetic particle precipitation is still poorly understood, and its representation in current atmospheric models is challenging (Funke, 2011). Odin/SMR, which is at present the only instrument measuring NO on a global scale, provides a very rich data set that can help the scientific community to get more information about the impact of EPP on the atmosphere.

Acknowledgements. The lead author is funded by the Swedish National Space Board (SNSB). Odin is a Swedish-led satellite project funded jointly by Sweden (SNSB), Canada (CSA), Finland (TEKES) and France (CNES). Odin is part of European Space Agency's (ESA) third party mission program. The authors would like to gratefully thank Y. Orsolini (NILU, Norway) for his helpful comments on this work.

Edited by: F. Khosrawi

\section{References}

Andrews, D. G., Holton, J. R., and Leovy, C. B.: Middle Atmosphere Dynamics, Academic Press, 489 pp., 1985.

Chandran, A., Collins, R. L., Garcia, R. R., Marsh, D. R., Harvey, V. L., Yue, J., and de la Torre, L.: A climatology of elevated stratopause events in the whole atmosphere community climate model, J. Geophys. Res., 118, 1234-1246, 2013.

Codrescu, M. V., Fuller-Rowell, T. J., Roble, R. G., and Evans, D. S.: Medium energy particle precipitation influences on the mesosphere and lower thermosphere, J. Geophys. Res., 102, 19977-19987, 1997.

Funke, B.: The High-Energy-Particle Precipitation in the Atmosphere (HEPPA) Model vs. Data Inter-comparison: Lessons Learned and Future Prospects, SPARC Newsletter, 36, 28-31, 2011. 
Funke, B., López-Puertas, M., Gil-López, S., von Clarmann, T., Stiller, G. P., Fisher, H., and Kellmann, S.: Downward transport of upper atmospheric $\mathrm{NO}_{\mathrm{x}}$ into the polar stratosphere and lower mesosphere during the Antarctique 2003 and Arctic 2002/2003 winters, J. Geophys. Res., 110, D24308, doi:10.1029/2005JD006463, 2005.

Funke, B., Baumgaertner, A., Calisto, M., Egorova, T., Jackman, C. H., Kieser, J., Krivolutsky, A., López-Puertas, M., Marsh, D. R., Reddmann, T., Rozanov, E., Salmi, S.-M., Sinnhuber, M., Stiller, G. P., Verronen, P. T., Versick, S., von Clarmann, T., Vyushkova, T. Y., Wieters, N., and Wissing, J. M.: Composition changes after the "Halloween" solar proton event: the High Energy Particle Precipitation in the Atmosphere (HEPPA) model versus MIPAS data intercomparison study, Atmos. Chem. Phys, 11, 9089-9139, doi:10.5194/acp-11-9089-2011, 2011.

Funke, B., López-Puertas, M., Stiller, G. P., and von Clarmann, T.: Mesospheric and stratospheric NOy produced by energetic particle precipitation during 2002-2012, J. Geophys. Res., 119, 4429-4446, 2014.

Goncharenko, L., Chau, J. L., Condor, P., Coster, A., and Benkevitch, L.: Ionospheric effects of sudden stratospheric warming during moderate-to-high solar activity: Case study of January 2013, Geophys. Res. Lett., 40, 4982-4986, doi:10.1002/grl.50980, 2013

Harvey, V. L., Randall, C. E., and Hitchman, M. H.: Breakdown of potential vorticity-based equivalent latitude as a vortex-centered coordinate in the polar winter mesosphere, J. Geophys. Res., 114, D22105, doi:10.1029/2009JD012681, 2009.

Holt, L. A., Randall, C. E., Harvey, V. L., Remsberg, E. E., Stiller, G. P., Funke, B., Bernath, P. F., and Walker, K. A.: Atmospheric effects of energetic particle precipitation in the Arctic winter 1978-1979 revisited, J. Geophys. Res., 117, D05315, doi:10.1029/2011JD016663, 2012.

Holt, L. A., Randall, C. E., Peck, E. D., Marsh, D. R., Smith, A. K., and Harvey, V. L.: The influence of major sudden stratospheric warming and elevated stratopause events on the effects of energetic particle precipitation in WACCM, J. Geophys. Res., 118, 636-646, 2013.

Labitzke, K. and Kunze, M.: On the remarkable Arctic winter in 2008/2009, J. Geophys. Res., 114, D00I02, doi:10.1029/2009JD012273, 2009.

Limpasuvan, V., Richter, J. H., Orsolini, Y. J., Stordal, F., and Kvissel, O.-K.: The roles of planetary and gravity waves during a major stratospheric sudden warming as characterized in WACCM, J. Atmos. Sol.-Terr. Phys., 78/79, 84-98, 2012.

Lossow, S., Urban, J., Eriksson, P., Murtagh, D., and Gumbel, J.: Critical parameters for the retrieval of mesospheric water vapour and temperature from Odin/SMR limb measurements at 557 GHz, Adv. Sp. Res., 40, 835-845, 2007.

Manney, G. L., Schwartz, M. J., Krüger, K., Santee, M. L., Pawson, S., Lee, J. N., Daffer, W. H., and Fuller, R. A.: Aura Microwave Limb Sounder observations of dynamics and transport during the record-breaking 2009 Arctic stratospheric major warming, Geophys. Res. Lett., 36, L12815, doi:10.1029/2009GL038586, 2009.

Murtagh, D. P., Frisk, U., Merino, F., Ridal, M., Jonsson, A., Stegman, J., Witt, G., Eriksson, P., Jiménez, C., Mégie, G., de la Noë, J., Ricaud, P., Baron, P., Ramon Pardo, J., Hauchecorne, A., Llewellyn, E. J., Degenstein, D. A., Gattinger, R. L., Lloyd, N. D., Evans, W. F. J., McDade, I. C., Haley, C. S., Sioris, C., von Savigny, C., Solheim, B. H., McConnell, J. C., Strong, K., Richardson, E. H., Leppelmeier, G. W., Kyrölä, E., Auvinen, H., and Oikarinen, L.: An overview of the Odin atmospheric mission, Can. J. Phys., 80, 309-319, doi:10.1139/P01-157, 2002.

Orsolini, Y. J., Urban, J., Murtagh, D. P., Lossow, S., and Limpasuvan, V.: Descent from the polar mesosphere and anomalously high stratopause observed in 8 years of water vapor and temperature satellite observations by the Odin Sub-Millimetre Radiometer, J. Geophys. Res., 115, D12, doi:10.1029/2009JD013501, 2010.

Randall, C. E., Rusch, D. W., Bevilacqua, R. M., Hoppel, K. W., and Lumpe, J. D.: Polar Ozone and Aerosol Measurement (POAM) II stratospheric $\mathrm{NO}_{2}$, 1993-1996, J. Geophys. Res., 103, 2836128371, 1998

Randall, C. E., Harvey, V. L., Singleton, C. S., Bailey, S. M., Bernath, P. F., Codrescu, M., Nakajima, H., and Russell III, J. M.: Energetic particle precipitation effects on the Southern Hemisphere stratosphere in 1992-2005, J. Geophys. Res., 112, D08308, doi:10.1029/2006JD007696, 2007.

Randall, C. E., Harvey, V. L., Siskind, D. E., France, J., Bernath, P. F., Boone, C. D., and Walker, K. A.: $\mathrm{NO}_{\mathrm{x}}$ descent in the Arctic middle atmosphere in early 2009, Geophys. Res. Lett., 36, L18811, doi:10.1029/2009GL039706, 2009.

Rusch, D. W., Gerard, L. C., Solomon, S., Crutzen, P. J., and Reid, G. C.: The effect of particle precipitation events on the neutral and ion chemistry of the middle atmosphere - 1. Odd nitrogen, Planet. Space Sci., 29, 767-774, 1981.

Sheese, P. E., Gattinger, R. L., Llewellyn, E. J., Boone, C. D., and Strong, K.: Nighttime nitric oxide densities in the Southern Hemisphere mesosphere-lower thermosphere, Geophys. Res. Lett., 38, L15812, doi:10.1029/2011GL048054, 2011.

Sheese, P. E., Strong, K., Gattinger, R. L., Llewellyn, E. J., Urban, J., Boone, C. D., and Smith, A. K.: Odin observations of Antarctic nighttime NO densities in the mesosphere-lower thermosphere and observations of a lower NO layer, J. Geophys. Res., 118, 7414-7425, 2013.

Siskind, D. E., Nedoluha, G. E., Randall, C. E., Fromm, M., and Russell III, J. M.: An assessment of southern Hemisphere stratospheric $\mathrm{NO}_{\mathrm{x}}$ enhancements due to transport from the upper atmosphere, Geophys. Res. Lett., 27, 329-332, 2000.

Solomon, S., Crutzen, P. J., and Roble, R. G.: Photochemical coupling between the thermosphere and the lower atmosphere: 1 . Odd nitrogen from 50-120 km, J. Geophys. Res., 87, 7206-7220, 1982.

Thorne, R. M.: The importance of energetic particle precipitation on the chemical composition of the middle atmosphere, Pure Appl. Geophys., 118, 128-151, 1980.

Tweedy, O. V., Limpasuvan, V., Orsolini, Y. J., Smith, A. K., Garcia, R. R., Kinnison, D., Randall, C. E., Kvissel, O.-K., Stordal, F., Harvey, V. L., and Chandran, A.: Nighttime secondary ozone layer during major stratospheric sudden warmings in specifieddynamics WACCM, J. Geophys. Res., 118, 1-13, 2013.

von Clarmann, T., Funke, B., López-Puertas, M., Kellmann, S., Linden, A., Stiller, G. P., Jackman, C. H., and Harvey, V. L.: The solar proton events in 2012 as observed by MIPAS, Geophys. Res. Lett., 40, 2339-2343, 2013. 